\title{
INVESTIGATING THE EFFECT OF CAPACITY CRITERION ON THE OPTIMAL ALLOCATION OF EMERGENCY FACILITIES IN GIS ENVIRONMENT
}

\author{
S. Bolouri ${ }^{1, *}$, A. Vafaeinejad ${ }^{2}$, A. Alesheikh ${ }^{3}$, H. Aghamohammadi ${ }^{4}$ \\ ${ }^{1}$ Department of GIS/RS, Science and Research Branch, Islamic Azad University, Tehran, Iran - samira_boloori@yahoo.com \\ ${ }^{2}$ Faculty of Civil, Water and Environmental Engineering, Shahid Beheshti University, Tehran, Iran - a_vafaei@ sbu.ac.ir \\ ${ }^{3}$ Department of Geospatial Information Systems, Faculty of Geodesy and Geomatics Engineering, K. N. Toosi University of \\ Technology, Tehran, Iran - alesheikh@kntu.ac.ir \\ ${ }^{4}$ Department of GIS/RS, Science and Research Branch, Islamic Azad University, Tehran, Iran - aghamohammadi@ srbiau.ac.ir
}

KEY WORDS: Capacity Criterion, Allocation, Tabu algorithm, Genetic algorithm, VAOMP, GIS

\begin{abstract}
:
Location-allocation analysis is one of the most GIS useful analysis, especially in allocating demands to facilities. One of these facilities is the fire stations, which the correct locations and optimal demand allocations to those have most importance. Each facility has a specific capacity that should be considered in locating the facilities and allocating the demand to those. In recent years, the use of unified models in solving allocation problems is too common because these models can solve a variety of problems, but in most of these models, the capacity criterion for facilities has been ignored. The present study tries to investigate the location-allocation problem of the fire stations with the aid of two Tabu and Genetic algorithms with the goal of maximizing the coverage using the (Vector Assignment Ordered Median Problem) VAOMP model, taking into account the capacity criterion and regardless of it. The results of using two algorithms in problem-solving show that the Genetic algorithm produces better quality solutions over a shorter time. Also, considering the capacity criterion that brings the problem closer to real-world space, in the study area, 59,640 demands will not be covered by any station within a 5-minute radius and will be highly vulnerable to potential hazards. Also, by adding 3 stations to the existing stations and re-allocating, the average of allocated demands with the help of Genetic was $93.39 \%$ and $92.74 \%$ for the Tabu algorithm. So it is necessary to consider the capacity of the facilities for optimal services.
\end{abstract}

\section{INTRODUCTION}

\subsection{Problem Statement}

Every year, there are many disastrous events around the world that require quick relief and emergency services such as fire stations. The inadequacy of these facilities and the lack of attention to the number of demands in the region can be risky. It is possible to investigate and solve the optimal allocation of demand using location-allocation analysis. Location-allocation problems are among the NP-hard issues (Yang et al., 2007), which will be difficult to solve them in exact methods. When the goals and criteria are added to the problem such as capacity, it will be much more difficult. Without considering this criterion, the facilities can allocate any number of demands to themselves while they are not able to service the demands optimally within a 5-minute standard radius. The usage of location-allocation models will be most effective in various problems.

Location-allocation analysis seeks to find optimal locations for facilities and optimal allocation of demands to facilities in GIS. Nowadays, GIS technologies are highly acceptable in the world (Vafaeinejad, 2018), and they are used in various applications (Vafaeinejad, 2017) and (Vahidnia et al., 2019). In GIS, location-location analysis has various models. But in general, there are four main models for the location-allocation problems, which are the P-median, the Simple Plant Location Problem
(SPLP), the P-center and Coverage (Brandeau and Chiu, 1989). There are many unified models that are a subset of these four basic models. In 1984, Hillsman by changing in the distance used from the median structure to solve many locationallocation problems (Hillsman, 1984). The Church and Weaver also provided the Vector Assignment P-median Problem (VAPMP), where each demand could be assigned to several facilities (Church and Weaver, 1986). Lei and Church (2014) developed a unified model (VAOMP) that can solve a variety of location and allocation problems. The present study uses this model to solve the fire station allocation problem with the goal of maximizing coverage with and without the capacity criterion integrated with GIS and also uses two Genetic and Tabu algorithms to solve the problem.

\section{LITERATURE REVIEW}

A lot of research has been done using location and allocation models and metaheuristic algorithms. Gabriei Crainic et al. used from a Tabu search algorithm to solve the median locationallocation problem. These show that Tabu search is a competitive method in solving the median problem (Gabriei Crainic et al., 1993). Neema et al. solved the multi-objective location-allocation problem by Genetic algorithm, and they used only 90 centers as demand points (Neema et al., 2010). In 2011 Shamsul Arifin solved the location-allocation of schools using Genetic and Simulated Annealing algorithm. He showed the Genetic algorithm was an effective method than Simulated

\footnotetext{
* Corresponding author
} 
Annealing in solving problems (Shamsul Arifin, 2011). Rasekh and Vafaeinejad (2012) developed a GIS-based decision support system for resource allocation an earthquake search. In 2013, Aghamohammadi et al. used a hybrid Genetic algorithm to optimize the allocation of the earthquake injuries to the treatment centers (Aghamohammadi et al., 2013). In 2016, Saeidian et al. compared two Genetic and Bees algorithms to solve the problem of locating and allocating the temporary relief centers during an earthquake using GIS. The results showed that the Genetic algorithm operates faster and more efficiently than the Bee algorithm to locate 9 relief centers (Saeidian et al., 2016). Lei et al., used from the Tabu search algorithm to solve a unified approach of Vector Assignment Ordered Median Problem for airports. The results of their research showed that the Tabu search produce better solutions than ILP method (Lei et al., 2016). In 2018, Bolouri et al. examined two Genetic and Simulated Annealing algorithms to solve the multi-objective location-allocation problem of fire stations in GIS environment. The results showed the efficiency of the Genetic algorithm with high demand (Bolouri et al., 2018).

Because in the various studies, Tabu and Genetic algorithm in solving location-allocation problems presented better results compared to other algorithms in less time and escaped from trapping in local optima, these two algorithms will be used to solve the location-allocation raised in this research. Too, Lei et al. (2016) showed that the Tabu search was an excellence method in solving VAOMP model. So, current research uses from Tabu and Genetic algorithm in fire stations locationallocation problem with VAOMP model.

\section{PROPOSED METHOD}

\subsection{VAOMP Model}

VAOMP can be as follows:

$$
Z=\sum_{i \in I} \lambda_{o(i)} z_{i} \quad z_{i}=\sum_{j \in X_{i j}} a_{i} \theta_{i x(i, j)} d_{i j}
$$

$i$ and $j$ are, respectively, the demand points and the facility. $p$ is a collection of selected facilities from facilities $J . a_{i}$ is the population in demand $i \in I$. $d_{i j}$ is the distance or the cost between demand $i$ and facility $j . \theta_{\text {in }}$ is the weight in demand $i$ in relation to the service of the lth level of the closest facility, where $1=1,2, \ldots \mathrm{L} . \mathbb{Z}_{\mathbb{t}}$ is the weighting distance (service level) assigned to i. $\lambda_{k}$ is the amount of weight associated with the kth level of the smallest demand based on the service level. The purpose of VAOMP is finding $\mathrm{p}$ to reach the lowest value of $\mathrm{Z}$ (Lei and Church, 2014). This model ranked the demands based on the problem goals and allocated the ranked demands to the facilities. This model is very applicable and can solve various type of problems.

\subsection{Genetic (GA) and Tabu Search algorithm (TS)}

The problem raised in this research is a combinatorial optimization. There are various meta-heuristics methods to solve these problems integrated with GIS such as Genetic, Simulated Annealing, Tabu, Game theory, and so on. But the Genetic algorithm is a powerful algorithm that it is looking for optimal or near optimal values. In the 1960s, John Holland thought about this algorithm, and he worked on it. In fact, the Genetic algorithm attempts to mimic the process of natural transformation using Genetic operators (selection, crossover, and mutation) (Didier Lins and López Droguett, 2011). Tabu search's algorithm is also a high-consumption and cost-effective metaheuristics for combined optimization problems (Habet,
2009). The Tabu search algorithm explicitly uses search history to escape from local minima and to implement a search strategy. The Tabu list length controls the memory of the search process. The smaller values of this list will allow the search to focus on smaller areas and conversely, the larger values of it explore larger areas to re-visit of more solutions that have been forbidden.

\subsection{Research Steps}

First, the data are prepared in GIS environment. Analysis are done, such as OD Cost Matrix analysis. The VAOMP model develops in the MATLAB environment with and without the capacity criterion. The proper parameters for the algorithms are determined by sensitivity analysis, and then the model on the study area is implemented with the goal of maximizing the coverage for the stations in a radius of 5 minutes. The results of the algorithms are compared. If a number of demands are without service then, relocation-reallocation is done to determine the optimal number of stations that cover the total demand by using two algorithms. Finally, the two algorithms are evaluated.

In the next phase, the VAOMP model is developed with the capacity criterion, and the two algorithms are again applied to allocate demands to existing stations. As in the first phase, if there are not enough existing stations to cover all demands, the number of suitable candidate stations with a capacity of 50,000 people (according to the universal standards (Yang et al., 2007)) is located by site selection and used to relocationreallocation using two algorithms. In other words, the number of demands without services is specified, and an estimate of the minimum number of stations for service is provided. Finally, in addition to examining the capability of the two algorithms, it is necessary to consider the capacity requirement in the allocation analysis of the emergency facilities. Figure 1 shows the steps of research.

\subsection{The Case Study}

In this research, the fire stations and the demands (population) of 21 and 22 provinces of Tehran are considered. The area, census zones, and demand data are gained from the latest census in the municipal website of 21 and 22 provinces. Corresponding the last census in Tehran, the population of two provinces is equal to 336600 persons. Figure 2 shows the study area and existing stations.

\section{RESULTS}

\subsection{Phase 1: Implementation of Uncapacitated VAOMP to Maximize the Coverage in Case Study}

The aim of this research is maximizing the coverage of the fire stations in Tehran, 21 and 22 provinces. This coverage problem is from MCLP $^{1}$ type that will be used to investigating the allocation status of existing fire stations. The VAOMP model can be converted into the MCLP problem by transforming the binary distance in relation (2) and with considering $\lambda_{1}=\lambda_{2}=\cdots=\lambda_{n}=1$ and $\theta=$ [1] (Church and Revelle, 1976). In other words, in the case of MCLP, each demand will be ranked at the OD Cost Matrix based on the maximum time (up to 5 minutes) and will be allocated to a station. Both algorithms are used separately to solve the problem.

\footnotetext{
1. Maximal Covering Location Problem
} 


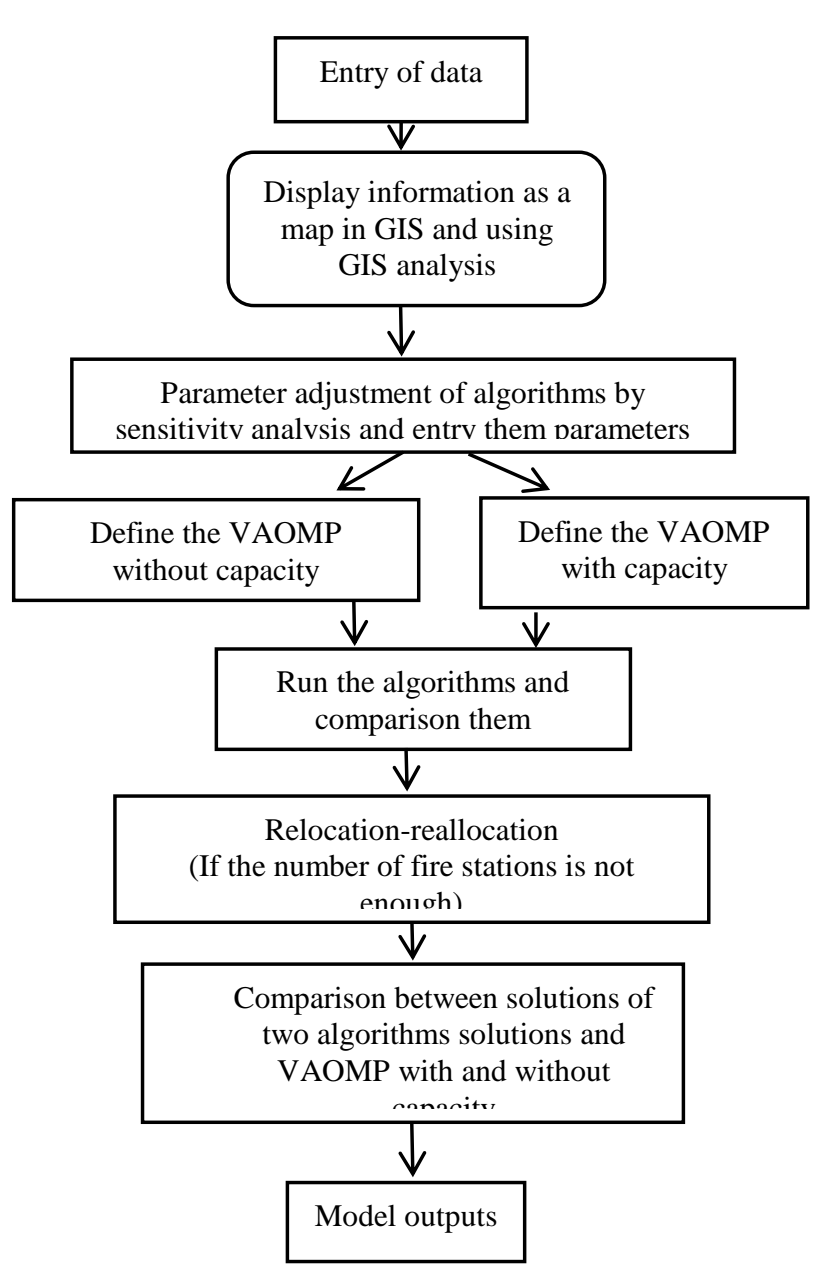

Figure 1. Steps of research

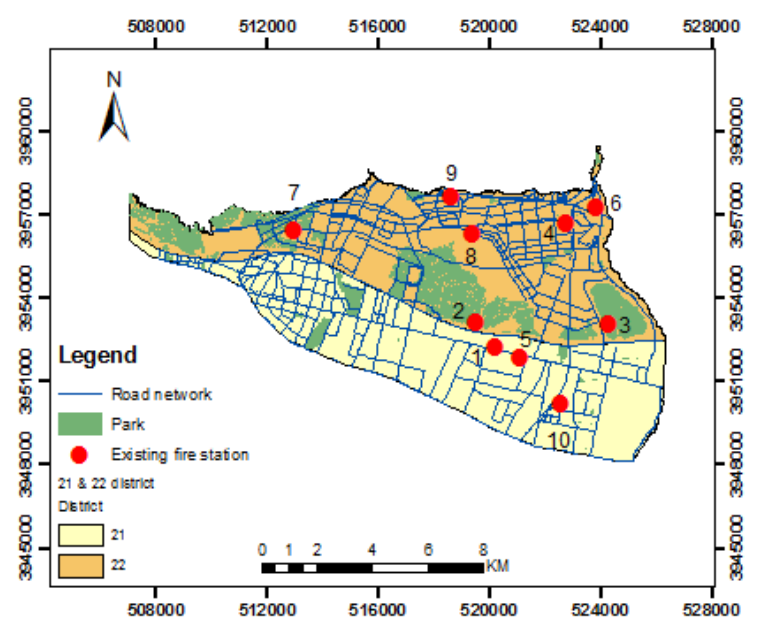

Figure 2. Study area

$d_{i j}^{n}=\left\{\begin{array}{lll}0 & \text { if } d_{i j} \leq s \\ 1 & \text { if } d_{i j}>s\end{array}\right.$

Given that at this stage the allocation status of existing fire stations is examined and the demands are ranked according to OD Cost Matrix, then the results and outputs of the two algorithms should be similar as shown in Figure 3 and Table 1. Table 1 and Figure 3 shows the results of allocation for existing fire stations by two algorithms.

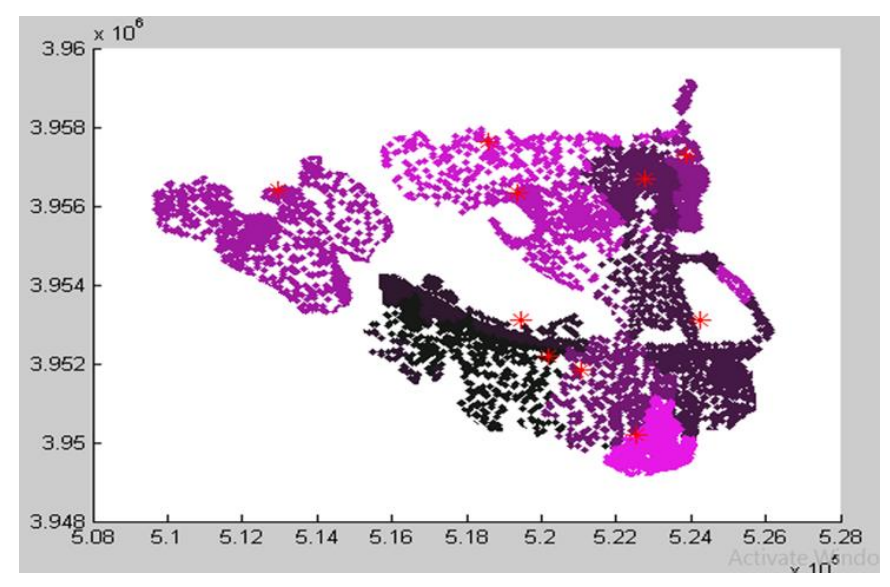

Figure 3. Results of allocation for existing fire stations by two algorithms

As Table 1 shows, there are 52840 demands left without service.

4.1.1 Comparison of both Algorithms and Investigation of the Model Validity: As expected, both algorithms generate the same optimal value because, with the help of the OD Cost Matrix, the maximum time of each demand is obtained from each station. So it is clear that each demand should be allocated to which station, and it is expected that even the allocation rate for each station is similar in two algorithms, which also shows the result, and this is the reason for the validation of the algorithms. Only the execution time of the algorithms are different, in which case the Genetic algorithm has less execution time.

4.1.2 Relocation-Reallocation to Service to All Demands Using Two Algorithms: Due to the insufficient number of existing stations with the goal of maximizing the stations coverage and without servicing the number of 52840 demands, by relocating and reallocating, that means fixing the existing stations and the selection of a number of stations from the candidate stations produced by locating, we choose the number of new stations. The number of existing stations in the region is 10 stations. In this paper, the purpose of relocation-reallocation is selecting 11 stations (10 existing stations and 1 new station among 35 candidate stations), 12 stations and 13 stations.

In metaheuristic algorithms, because in each execution is produced a different solution than other executions, to evaluate the solution robustness, it is necessary to use the repeatability test. In this way, we compare the results obtained from a certain number of consecutive performances with the same parameters in terms of convergence, and if the obtained solutions do not differ significantly, we can say that the algorithm in terms of solving problems is the strength ones.

In order to investigate the strength of developed methods and the average execution time of each of the methods, the experiments were designed according to the number of fire stations, which included 11,12 and 13 stations. Each of these states was solved 10 times by two algorithms. Then, for each set of designed experiments, normalized standard deviation of the obtained solutions for two methods was calculated, which the obtained accuracy for different states was shown in Table 2 . Table 3 shows the average optimal values for 10 times execution for each target function. 
Table 1. Results of allocation for existing fire stations by two algorithms

\begin{tabular}{|c|c|c|c|c|c|c|c|c|c|c|}
\hline No. Stations & 1 & 2 & 3 & 4 & 5 & 6 & 7 & 8 & 9 & 10 \\
\hline $\begin{array}{c}\text { No. Allocated } \\
\text { demands }\end{array}$ & 14000 & 18040 & 54120 & 25240 & 17360 & 54920 & 18600 & 18400 & 10800 & 52280 \\
\hline $\begin{array}{l}\text { Execution time } \\
\text { (TS) }\end{array}$ & \multicolumn{10}{|c|}{495.371} \\
\hline $\begin{array}{c}\text { Execution time } \\
\text { (GA) }\end{array}$ & \multicolumn{10}{|c|}{342.220} \\
\hline Optimal value & \multicolumn{10}{|c|}{310880} \\
\hline No. Demands & \multicolumn{10}{|c|}{336600} \\
\hline $\begin{array}{l}\text { No. Not } \\
\text { allocated } \\
\text { demands }\end{array}$ & \multicolumn{10}{|c|}{52840} \\
\hline
\end{tabular}

Table 2. Normalized standard deviation of obtained solutions from the objective function for two algorithms

\begin{tabular}{|c|c|c|}
\hline $\begin{array}{c}\text { No. Fire } \\
\text { stations }\end{array}$ & $\begin{array}{c}\text { Normalized } \\
\text { standard } \\
\text { deviation of } \\
\text { obtained } \\
\text { solutions based } \\
\text { on TS }\end{array}$ & $\begin{array}{c}\text { Normalized } \\
\text { standard } \\
\text { deviation of } \\
\text { obtained } \\
\text { solutions based } \\
\text { on GA }\end{array}$ \\
\hline 11 & 0.0293 & 0.0281 \\
\hline 12 & 0.0309 & 0.0307 \\
\hline 13 & 0.0377 & 0.0321 \\
\hline
\end{tabular}

Table 3. Average optimal solutions with 10 times execution for two algorithms

\begin{tabular}{|c|c|c|}
\hline $\begin{array}{c}\text { No. Fire } \\
\text { stations }\end{array}$ & $\begin{array}{c}\text { Average of the } \\
\text { optimal } \\
\text { solutions based } \\
\text { on TS }\end{array}$ & $\begin{array}{c}\text { Average of the } \\
\text { optimal solutions } \\
\text { based on GA }\end{array}$ \\
\hline 11 & 306960 & 307160 \\
\hline 12 & 323000 & 323160 \\
\hline 13 & 336520 & 336600 \\
\hline
\end{tabular}

As the Table 3 shows, with the increase in the number of stations, the average value of the objective function is increased, because with increasing the number of stations, demands can be assigned to their optimal ones. Since the final output of these methods represents the number of the demand allocations to each station, then the second criterion which is examined for the robustness of the solutions, is the difference in allocations in different replications. The proportion of the demands that are assigned the same in every 10 replicates of the experiment for total demands are considered as the evaluation criterion. In Table 4, the obtained value for different states has been shown for two methods.

Table 4. Comparing the allocation accuracy of the obtained results for two algorithms

\begin{tabular}{|c|c|c|}
\hline $\begin{array}{c}\text { No. Fire } \\
\text { stations }\end{array}$ & $\begin{array}{c}\text { Allocation } \\
\text { accuracy based on } \\
\text { TS }\end{array}$ & $\begin{array}{c}\text { Allocation } \\
\text { accuracy based on } \\
\text { GA }\end{array}$ \\
\hline 11 & 94.3 & 98 \\
\hline 12 & 90.4 & 95 \\
\hline 13 & 86.6 & 90.1 \\
\hline
\end{tabular}

As it is known, with increasing the number of stations due to the complexity of the problem space, the allocation accuracy in all two methods has been reduced. The fourth parameter evaluates the average percentage of total allocated demands for two algorithms. The results have been shown in Table 5 .

Table 5. Average percentage of total allocated demands for two algorithms

\begin{tabular}{|c|c|c|}
\hline $\begin{array}{c}\text { No. Fire } \\
\text { stations }\end{array}$ & $\begin{array}{c}\text { Average percentage } \\
\text { of total allocated } \\
\text { demands based on } \\
\text { TS }\end{array}$ & $\begin{array}{c}\text { Average percentage } \\
\text { of total allocated } \\
\text { demands based on } \\
\text { GA }\end{array}$ \\
\hline 11 & 88.781 & 88.883 \\
\hline 12 & 98.867 & 98.954 \\
\hline 13 & 99.999 & 99.999 \\
\hline
\end{tabular}

The last examined parameter is the problem-solving time that is measured during testing. In Table 6 , the average solving time has been shown for the two methods.

Table 6. Comparison of the average solving time in seconds for two algorithms

\begin{tabular}{|c|c|c|}
\hline $\begin{array}{c}\text { No. Fire } \\
\text { stations }\end{array}$ & $\begin{array}{c}\text { Average solving } \\
\text { time based on } \\
\text { TS }\end{array}$ & $\begin{array}{c}\text { Average solving } \\
\text { time based on GA }\end{array}$ \\
\hline 11 & 557.858 & 347.589 \\
\hline 12 & 634.886 & 438.187 \\
\hline 13 & 650.128 & 475.987 \\
\hline
\end{tabular}

Regarding the studied parameters, it can be said that the Genetic method has more stability and strength than the TS method. Also, the Genetic algorithm is better than the TS algorithm in terms of the quality of the produced solutions.

4.2 Phase 2: Implementation of Capacitated VAOMP to Maximize the Coverage in Case Study

This phase will be done the same as section 4.1, and the capacity criterion will be only added to function (1). This criterion will be as follows: 


\section{$\sum_{i=1} \sum_{k=1}^{n} c_{i j}^{l} \leq C_{j} \quad$ for each $j \in J$}

This constraint states that the sum of allocations for each facility should be less than or equal to its capacity. Both algorithms are used separately to solve the problem.

The first time, the TS and GA algorithm with their adjusted parameters are used to maximize the coverage of fire stations up to a radius of 5 minutes to check the demand allocation in area. Allocation results have been shown in Figure 4 (unallocated demands have not been shown in the figure). The results of allocation in each station and unallocated demands have been also presented in Table 7. Too, given that at this stage the allocation status of existing fire stations is examined and the demands are ranked according to OD Cost Matrix, then the results and outputs of the two algorithms should be similar as shown in Figure 4 and Table 7. As Table 7 shows, there are 59640 demands left without service.

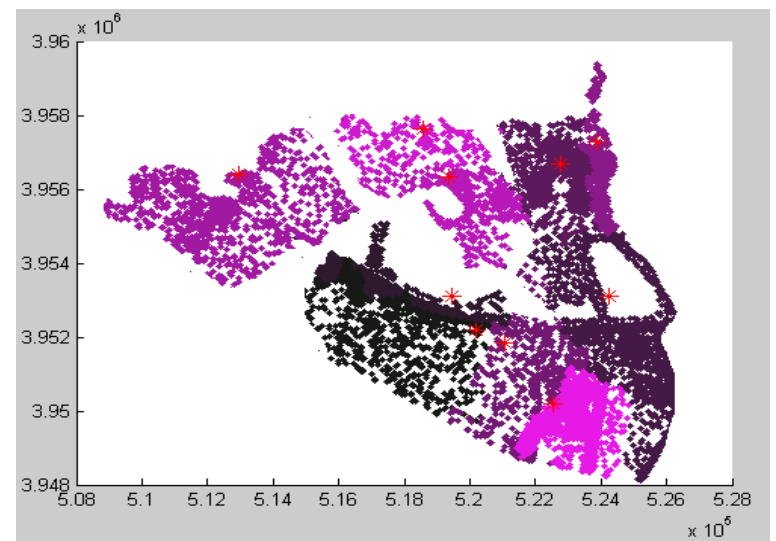

Figure 4. Results of allocation for existing fire stations by two algorithms

Table 7. Results of allocation for existing fire stations by two algorithms

\begin{tabular}{|c|c|c|c|c|c|c|c|c|c|c|}
\hline No. Stations & 1 & 2 & 3 & 4 & 5 & 6 & 7 & 8 & 9 & 10 \\
\hline $\begin{array}{l}\text { No. Allocated } \\
\text { demands }\end{array}$ & 16400 & 18040 & 50000 & 24240 & 20360 & 47000 & 19600 & 18400 & 12920 & 50000 \\
\hline $\begin{array}{c}\text { Execution time } \\
\text { (TS) }\end{array}$ & \multicolumn{10}{|c|}{535.212} \\
\hline $\begin{array}{c}\text { Execution time } \\
\text { (GA) }\end{array}$ & \multicolumn{10}{|c|}{421.366} \\
\hline Optimal value & \multicolumn{10}{|c|}{276960} \\
\hline No. Demands & \multicolumn{10}{|c|}{336600} \\
\hline $\begin{array}{l}\text { No. Not } \\
\text { allocated } \\
\text { demands }\end{array}$ & \multicolumn{10}{|c|}{59640} \\
\hline
\end{tabular}

\subsubsection{Comparison of both Algorithms and Investigation of the Model Validity:}

In Table 7, as expected, two algorithms produce the same optimal value because, with the help of the OD Cost Matrix, the maximum time of each demand with each station is obtained, so it is clear that each demand should be assigned to which station. So, it is expected that even the allocation of each station in each algorithm is similar, that also the results show the same, and this is the reason for the model validity. Only, the execution time of the two algorithms is different, in which case the Genetic algorithm has less execution time.

On the other hand, by comparing Tables 7 and 1, we find that the number of allocated and unallocated demands is not the same in both cases, and even the number of allocations of each station is different because the maximum coverage is due to an increase in the coverage radius of up to 5 minutes. As a result, after arranging the OD Cost Matrix from the highest to the lowest value, first, higher demands are allocated to each station until the station capacity is filled up and so when the capacity of a station was filled, other demands at lower levels can't be allocated to that station and they may be assigned to another station, or they may not be assigned to any other station with respect to the radius of operation up to 5 minutes. Too, the results show in this section, the more demands have been not allocated.

Too, except for the demands that coverage radius for them are more than 5 minutes, and can't be allocated to any station, there are the number of demands that their station capacity is filled up and can't be allocated to that station, then the number of unallocated demands in the state of capacitated and uncapacitated stations is difference, and they increase in a capacitated state. Also, in this case, there are 59640 demands 1 without stations, so in the next section will fix the problem by adding several stations and performing relocation-reallocation.

\subsubsection{Relocation-Reallocation to Service to All Demands Using Two Algorithms:}

Given the insufficient number of stations with the goal of maximizing station coverage and 59640 non-serving demands, by relocating and reallocating, that's mean, fixing the existing fire stations and selecting several stations among the candidate stations produced by locating, select several new stations. In this section too, same as section 4.1.2, the aim is selecting 11 , 12 and 13 stations and same as section 4.1.2 for two methods, the normalized standard deviation of obtained solutions from the objective function in Table 8 , the average of the optimal solutions in Table 9, the allocation accuracy of the obtained results in Table 10, the average percentage of total allocated demands in Table 11 and the average solving time in Table 12 have been calculated. 
Table 8. Normalized standard deviation of obtained solutions from the objective function for two algorithms

\begin{tabular}{|c|c|c|}
\hline $\begin{array}{c}\text { No. Fire } \\
\text { stations }\end{array}$ & $\begin{array}{c}\text { Normalized } \\
\text { standard } \\
\text { deviation of } \\
\text { obtained } \\
\text { solutions based } \\
\text { on TS }\end{array}$ & $\begin{array}{c}\text { Normalized } \\
\text { standard } \\
\text { deviation of } \\
\text { obtained } \\
\text { solutions based } \\
\text { on GA }\end{array}$ \\
\hline 11 & 0.0428 & 0.0356 \\
\hline 12 & 0.0564 & 0.0414 \\
\hline 13 & 0.1114 & 0.0919 \\
\hline
\end{tabular}

Table 9. Average optimal solutions with 10 times execution for two algorithms

\begin{tabular}{|c|c|c|}
\hline $\begin{array}{c}\text { No. Fire } \\
\text { stations }\end{array}$ & $\begin{array}{c}\text { Average of the } \\
\text { optimal } \\
\text { solutions based } \\
\text { on TS }\end{array}$ & $\begin{array}{c}\text { Average of the } \\
\text { optimal solutions } \\
\text { based on GA }\end{array}$ \\
\hline 11 & 287440 & 289600 \\
\hline 12 & 299960 & 304160 \\
\hline 13 & 309600 & 313040 \\
\hline
\end{tabular}

Table 10. Comparing the allocation accuracy of the obtained results for two algorithms

\begin{tabular}{|c|c|c|}
\hline $\begin{array}{c}\text { No. Fire } \\
\text { stations }\end{array}$ & $\begin{array}{c}\text { Allocation } \\
\text { accuracy based on } \\
\text { TS }\end{array}$ & $\begin{array}{c}\text { Allocation } \\
\text { accuracy based on } \\
\text { GA }\end{array}$ \\
\hline 11 & 92.3 & 97.5 \\
\hline 12 & 88.5 & 93.1 \\
\hline 13 & 80 & 87.4 \\
\hline
\end{tabular}

Table 11. Average percentage of total allocated demands for two algorithms

\begin{tabular}{|c|c|c|}
\hline $\begin{array}{c}\text { No. Fire } \\
\text { stations }\end{array}$ & $\begin{array}{c}\text { Average percentage } \\
\text { of total allocated } \\
\text { demands based on } \\
\text { TS }\end{array}$ & $\begin{array}{c}\text { Average percentage } \\
\text { of total allocated } \\
\text { demands based on } \\
\text { GA }\end{array}$ \\
\hline 11 & 83.01 & $84.92^{\wedge}$ \\
\hline 12 & 89.31 & 90.01 \\
\hline 13 & 92.74 & 93.32 \\
\hline
\end{tabular}

Table 12. Comparison of the average solving time in seconds for two algorithms

\begin{tabular}{|c|c|c|}
\hline $\begin{array}{c}\text { No. Fire } \\
\text { stations }\end{array}$ & $\begin{array}{c}\text { Average solving } \\
\text { time based on } \\
\text { TS }\end{array}$ & $\begin{array}{c}\text { Average solving } \\
\text { time based on GA }\end{array}$ \\
\hline 11 & 562.141 & 480.220 \\
\hline 12 & 645.398 & 485.647 \\
\hline 13 & 649.991 & 492.325 \\
\hline
\end{tabular}

As the Tables 9-12 show, with the increase in the number of stations, the average value of the objective function, the average percentage of total allocated demands, the average solving time and the normalized standard deviation is increased because the number of stations is increased so, demands can be assigned to their optimal ones then, the average percentage of total allocated demands is increased too. Besides, the complexity of the problem increases, so, solving time is increased and the allocation accuracy in two methods is decreased.

But, comparing Tables 8-12 to 2-6, the value of objective function and the percentage of total allocated demands have been decreased because the number of demands can't be allocated to any station due to capacity criterion, the normalized standard deviation, and the solving time have been increased, and allocation accuracy has been decreased because the complexity of the problem.

Regarding the parameters studied, it can be said that the Genetic method has more stability and strength than the Tabu search method. Also, the Genetic algorithm is better than the TS algorithm in terms of the quality of the solutions and the solving time.

\section{CONCLUSIONS}

Considering that the condition of capacity is one of the most important conditions in the analysis of the demand allocation to the facilities and in most models this condition has been ignored, the present study examines the effect of the capacity condition that has been ignored in the VAOMP model. Two algorithms separately allocated the demands to the facilities in the study area with the goal of maximizing coverage radius for the existing stations. First, the uncapacitated VAOMP model implemented in the study area. The allocation results of the existing stations with the help of both algorithms showed that 52840 people would be without access to services, while both algorithms showed similar results, but the convergence speed of Genetic was higher in reaching the optimal solutions. Therefore, by creating candidate stations and performing relocation and reallocation, the optimal number of stations to cover demands was examined. The results of both algorithms showed that 13 stations are needed to cover $99.99 \%$ of demands.

In the next stage, the capacitated VAOMP model with a capacity of 50,000 people for each station was developed and again examined the allocation status of existing stations. The results showed that 59640 demands remained without services. Therefore, by relocating and reallocating, it was found that with the help of 13 stations, the average of allocated demands with Genetic was equal to $93.39 \%$ and for Tabu algorithm was $92.74 \%$. Also, the Genetic algorithm had a higher quality than the Tabu. Thus, even 13 stations are not sufficient to serve all regional demands, and failure to comply with this condition means that there will be some demands without services, and this may even make serious risks.

\section{REFERENCES}

Aghamohammadi, H., Mesgari, M., Molaei, D., Aghamohammadi, H., 2013. Development a heuristic method to locate and allocate the medical centers to minimize the earthquake relief operation time. Iranian Journal of Public Health, 42(1), 63-71.

Bolouri, S., Vafaeinejad, A., Alesheikh, A., Aghamohammadi, H., 2018. The ordered capacitated multi-objective locationallocation problem for fire stations. ISPRS International Journal of Geo-Information, 7(2), 44.

Brandeau, M.L. and Chiu, S., 1989. An Overview of representative problems in location research. Management Science, 33, 645-674. 
Church, R.L. and Revelle, C.S., 1976. Theoretical and computational links between the p-median, location setcovering, and the maximal covering location problem. Geographical Analysis, 8(4), 407-415.

Church, R.L. and Weaver, J.R., 1986. Theoretical links between median and coverage location problems. Annals of Operations Research, 6 (1), 1-19.

Didier Lins, I. and López Droguett, E., 2011. Redundancy allocation problems considering systems with imperfect repairs using multi-objective genetic algorithms and discrete event simulation. Simulation Modelling Practice and Theory, 19, 362-381.

Gabriei Crainic, T., Gendreau, M., Soriano, P., Toulouse, M., 1993. A tabu search procedure for multicommodity requirements. Annals of Operations Research, 41(4), 359-383.

Habet, D., 2009. Tabu search to solve real life combinatorial optimization problems: a case of study. Foundations of Computational Intelligence, 3, 129-51.

Hillsman, E.L., 1984. The P-median structure as a unified linear model for location-allocation analysis. Environment and Planning A, 16, 305-318.

Lei, T.L. and Church, R.L., 2014. Vector assignment ordered median problem: a unified median problem. International Regional Science Review, 37(2), 194-224.

Lei, T., Church, R., Lei, Z., 2016. A unified approach for location- allocation analysis: integration GIS, distributed computing and spatial optimization. International Journal of Geographic Information Science, 30, 515-534.

Neema, M.N. and Ohgai, A., 2010. Multi-objective location modelling of urban parks and open spaces: continuous optimization. Computers, Environment and Urban Systems, 34, 359-376.

Rasekh, A. and Vafaeinejad, A.A., 2012. Developing a GIS based decision support system for resource allocation in earthquake search and rescue operation. Lecture Notes in Computer Science, 7334, 275-285.

Saeidian, B., Mesgari, M., Ghodousi, M., 2016. Evaluation and comparison of Genetic algorithm and Bees algorithm for location-allocation of earthquake relief centers. International Journal of Disaster Risk Reduction, 15, 94-107.

Shamsul Arifin, M. D., 2011. Location allocation problem using genetic algorithm and simulated annealing: a case study based on school in Enschede, Master thesis, Department in Geoinformation Science and Earth Observation, University of Twente.

Vafaeinejad, A., 2017. Dynamic guidance of an autonomous vehicle with spatio-temporal GIS. Lecture Notes in Computer Science, LNSC, 10407, 502-511.

Vafaeinejad, A., 2018. Design and implementation of a dynamic GIS with emphasis on navigation purpose in urban area. ICCSA (1), 667-675.

Vahidnia, M.H., Vafaeinejad, A.R., Shafiei, M., 2019. Heuristic game-theoretic equilibrium establishment with application to task distribution among agents in spatial networks. Journal of Spatial Science, 64(1), 131-152.

Yang, L., F.Jones, B., Yang, S., 2007. A fuzzy multi-objective programming for optimization of fire station locations through genetic algorithms. European Journal of Operational Research, 181, 903-915. 